\title{
A Nordic Congress on Migration Research
}

In the end of August 1967 a conference on migration research problems took place in Växjö, Sweden, arranged by the universities of Lund and Uppsala and by the Emigration Institute in Växjö. The purpose of the conference was to enable university as well as local researchers in this field from various places in the Nordic countries and also from the USA to meet. discuss and establish contacts for further co-operation and the exchange of information.

\section{PROBLEMS IN CONNECTION WITH MIGRATION RES- EARCH}

was the title of the lecture with which Sten Carlsson, professor of History at the University of Uppsala began the proceedings. $\mathrm{He}$ emphasized the great and rapid expansion in the field, which has taken place in Sweden during the sixties. Among the causes of this expansion he mentioned the generally favourable situation for historical research in Sweden and the increased use of co-operation in teams on different subjects, the fact that the possibilities of obtaining accession to both official and private source material are very good at present, especially in Sweden, and that the migration problems have got more actual and accentuated lately, i. e. because of the growing interest for social history and the actual migration movements in Europe. He also mentioned some typical subjects for rese- arch, such as the possible connection between internal and external migration, emigration via earlier movements from the countryside to the urban areas. contacts between different Swedish and American areas, the process of assimilation in the USA, the re-immigration to Sweden etc.

\section{REPORTS ON MIGRATION RESEARCH IN THE NORDIC COUNTRIES}

were delivered by scholars from the different Nordic countries.

\section{Norway}

Ingrid Semmingsen, professor of American history at the University of Oslo and the author of »Veien mot vesba, the great history of Norwegian emigration to America, reported on Norwegian migration research to-day.

\section{Finland}

Reino Kero, fil mag of the University of Turku (Abo) presented the migration aesearch group there and also gave some basic information about the emigration from Finland.

\section{Danmark}

Kristian Hvidt, cand. mag. from the University of Copenhagen, who himself is occupied with an extensive investigation of the Danish emigration, presented his work, especially the very promising trials with data processing for this kind of historical research. 


\section{Sweden}

Birgitta Odén, pnofessor of history at the University of Lund, presented the migration studies in Lund, and finally Sune Akerman, assistant professor and head of the section of American history at the University of Uppsala, delivered a report on the work and results of the project $\gg$ Sweden and America 1860-1930; emigration, re-immigration, political and social debate),

\section{THE LOCAL EMIGRATION RESEARCH}

Sigurd Gustavsson, director of the Emigration Register in Karlstad introduced a discussion on the local emigration research by giving a report on the work of this kind of research, its methods, problems and purposes. He especially stressed the importance of good contacts and competent aid in the municipalities and parishes. The local folk societies have often proved to be the most valuable source for the local work.

After discussions in special groups, based upon a memorandum composed by Ulf Ebbeson, University of Uppsala, the participants in the conference delivered reports and points of view in the concluding debate. Special stress was laid upon the fact, that migration studies on the university level often are dependent on the works of local historians - especially in connection with the collection of certain source material and other means of obtaining knowledge, which presuppose familiarity with local circumstances.
The poor comordination between local researchers and university scholars was remarked upon as a very regrettable deficiency. The wish was expressed that county committees should try to co-ordinate the municipal and parish projects, whereby the contribution of the universities for practical reasons ought to be confined to the county committees.

\section{EMIGRATION AND OPINION RESEARCH}

This part of the conference was started by Kjell Bondestad, University of Uppsala, who gave a lecture on Swedish pness opinion during the American Civil War.

Birgitta Odén discussed different studies of opinion, how to define them and how to find and use applicable methods. She stressed the danger of mixing facts at i.e. »the people's opinion, with the opinion expressed in the newspapers,.. Regarding press studies the researcher ought to select his material and his methods carefullv according to the aims of the study. She also gave a review of the available material for opinion study in the migration field, such as newspapers - Swedish and Swedish-American -, letters, interviews and different kinds of official material.

Magdalena Hellquist, librarian at Royal library of Stockholm, gave an account of the Swedish-American press and of the extensive collection of this kind of newspapers belonging to the Royal library of Stockholm. 
THE IMMIGRANT IN THE USA

The immigrant's situation was after that discussed in a lecture by John Higham, professor at the University of Michigan, USA. He talked about the effects of mass immigration on the American society and culture. The lecture which was commented by Dr Håkan Berggren, University of Uppsala, will later be reprinted in the American Studies in Scandinavia and further details will therefore not be given here.

THE ARCHIVES AND THE, COLLECTION OF SOURCE MATERIAL

The Head of the National Archives, Dr. Åke Kromnow, Stockholm, talked of private archives, the necessity of saving and inventing them and how this could most easily be done. This problem is of course connected with that of the collection of material for the benefit of the migration researchers.

Personal visits to owners of private archives have proved to give incomparably the best results, though it is unfortunately a rather expensive way of collecting material.

Dr. Folke Hedblom, assistant professor at the University of Uppsala, gave an example of material collecting. of a somewhat different kind. He gave a report on his journeys in North America, where he has taped Swedish dialects - both old "preserved" dialects and the »mixed language», which gradually developed among the immigrants.
CONCLUDING DISCUSSION AND RESOLUTIONS

The conference was finished by a panel discussion on migration research on the university level. The participants, among whom were also representatives for Sociology and Economics, expressed as their view that co-operation with other sciences ought to be much more fruitful than a strict limitation of the subject. Especially the social sciences, i. e. Sociology, Economics, Geography etc, might give valuable contributions to the migration research. The actual research concerning the structure of the labour market was mentioned as an example of successful co-operation with social scientists. The convenience of working in teams at the universities was stressed as was likewise the importance of extensive international contacts and exchange of information.

As a conclusion the meeting worked out a resolution in five points, in which the following wishes were expressed:

1. Increased co-operation between migration researchers in the Nordic countries and in North America ought to be aimed at.

2. Increased co-operation ought to take place between the university and the local migration research, for example concerning planning, collecting and keeping of source material, registration and excerption, scientific works and publications.

3. The collecting, registrating and copying work going on in the Nordic countries and in North America ought to be intensified and 